\title{
DOES IT PAY THE AVERAGE COAL MINE TO PURCHASE CENTRAL STATION POWER?
}

\author{
BY GRAHAM BRIGHT
}

In the application of central station power to coal mines the successful operator of today is sometimes at a loss to know just what saving will be effected, for the following reasons: first, he believes that he is producing power at a fairly low cost, due to cheap fuel, simple apparatus and low cost of buildings; second, not knowing approximately his costs in detail, he is at first unable to see his saving, if any, as compared with a definite rate per kw-hr. for central station power; third, the use of central station energy often requires the purchasing of new apparatus, and the selling of the present generating apparatus under unfavorable conditions.

In regard to the first reason, the cost of fuel is, of course, low at the mine, but ifs value should be figured at the price that could be obtained for it if sold. The water question is often a serious one, and bad water in many cases occasions heavy repairs. The boilers, engines and generators as a rule are the simplest and cheapest obtainable, there being very little incentive tor high economy at a mine power plant. Reliability is the first requisite. and with the class of skilled help obtainable about a mine, this reliability can be obtained only with the simplest kind of apparatus. The buildings are generally of the cheaper construction, and often have inadequate illumination, in which case the equipment does not receive the care it should.

In regard to the second reason, a certain rate per kw-hr. for power from a central station is not always an indication to the average operator as to what his total cost for power and his saving will be. 
In regard to the third reason, in order to utilize central station energy it is usually necessary to purchase motors to replace the fan, hoist and compressor engines, and to purchase synchronous converters or motor-generator sets to replace the generators and engines driving them. The boilers, engines, pumps, old generators and piping must be sold and it is rather difficult to get much more than scrap value for these, if they have been in use for several years. If the proper depreciation on the old apparatus has been charged off each year, the value carried on the books should not be very high. The difference between the value of the old apparatus and the salvage obtained for it must be charged off, or the entire value of the old apparatus must be charged off and the value of the new apparatus put on the books as the difference between the cost of the new apparatus and the salvage obtained for the old. To provide for this change new capital is required, and the members of the average board of directors must be assured of adequate returns before they will permit the expenditure of this new capital.

The purpose of this paper is to show a method of obtaining the cost of power at an average coal mine with its own power plant, and what the cost would be if central station energy were purchased at some definite rate per $\mathrm{kw}-\mathrm{hr}$. The values assumed are only approximate, as it is the method that is to be shown rather than actual values.

We will suppose that we are investigating a shaft mine, having the following list of power apparatus:

4 return tubular boilers, $18 \mathrm{ft}$. by 72 in. ( 549 by $183 \mathrm{~cm}$.) Steam pressure, $90 \mathrm{lb}$. (40.8 kg.).

2 boiler feed pumps.

1 deep well pump.

1 feed water heater.

1 double balanced steam hoist. Max. h.p. of engine, 400.

1 ventilating fan. Horse power of engine, 50.

2 high-speed 150-h.p. engines for generators.

2 100-kw. 500-volt d-c. belted generators.

1 10-h.p. engine for machine shop.

1 10-h.p. " " screen.

1 25-h.p. " “ elevator.

1 5-h.p. " " coal conveyer to boiler room.

2 steam pumps at bottom of shaft, 10 h.p. each.

The motors operated from the generators will have a combined capacity of about 500 h.p. The generators will be operated about twenty hours per day, the time depending upon the amount of electric pumping to be done. Some of the coal cut- 
ting is frequently done at night, which tends to improve the load factor on the generators, the lights and pump load being, as a rule, a small percentage of the capacity of one generator. The hoist will operate eight hours per day, with an occasional trip at night, or on non-working days. The fan will operate 24 hours per day. The tipple engines will work eight hours per day, and the steam pumps and coal conveyor will work intermittently.

The mine under consideration has an average output of 1,100 tons* per day, and operates on an average 18 days per month all the year round. On days that the mine does not operate, one generator must be run to supply power for the pumps, lights and locomotives doing special work.

The operating force will consist of the following:

1 day engineer for the hoist.

1 " " " " electric plant.

1 night " " " " "

1 day fireman

1 day fireman's helper for wheeling ashes and helping around boiler room.

1 night fireman.

The wages of extra repairmen will be included in upkeep and repair charges.

The amount of coal used under the boilers will be about 500 tons per month, and this coal being slack, or a mixture of nut, pea and slack, its value will be about fifty cents per ton. In some plants it is necessary to use run-of-mine under the boilers, in which case the value is considerably higher.

To obtain the cost of power per kw-hr., it is of course necessary to first find out how many kilowatt-hours per day or per month are being produced. It is best to figure the costs on a monthly or yearly basis, in order to take into account the time lost when the mine is not operating. The cost per ton output for power will depend somewhat on the number of days per month or per year the mine operates, since a number of the items of expense go on just the same whether the mine operates or not. In this paper the costs will be figured on a monthly basis, taking the working days as the average per month for a year:

When obtaining the total kilowatt-hours the load factor should be determined at the same time, since the rate of charge

\footnotetext{
${ }^{*} 1$ long ton $=1.01605$ metric tons.
} 
by the central station often depends upon the load factor. The load factor should be figured on the total five-minute or some other short time peak rather than on the capacity of existing machines, since the engines and generators installed are often very much larger than necessary, and their capacity is seldom reached by even momentary peaks.

The electrical kilowatt-hours, momentary and five-minute peak loads can easily be obtained by placing a watt-hour meter and graphic recording wattmeter or ammeter in the circuit of the generators for a 24-hour rin, both for a working and a nonworking day. The power developed by the steam engines driving fans, hoists, etc., is more difficult to obtain. If possible, these engines should be indicated, and from the cycle of operation, the horse power-hours or kilowatt-hours can be computed for a working and non-working day. Where it is not possible to use an indicator, the power taken by the fan engine may be calculated approximately from the size and speed of the engine; steam pressure, size and speed of fan, air pressure, and volume of air in cubic feet per minute. The power required by the hoist can be figured from the work being done and checked by the size and speed of the engine and the steam pressure. It is best to place the information in tabular form, so that ready comparison may be made. Table I shows the method of obtaining the total kilowatt-hours per month and the load factor.

TABLE I.-Capacity, KW-Hr. and Load Factors.

\begin{tabular}{|c|c|c|c|c|c|}
\hline Machines & $\begin{array}{c}\text { Five-min. } \\
\text { peak }\end{array}$ & $\begin{array}{c}\text { Capacity } \\
\text { in } \mathrm{kw}-\mathrm{hr} \text {. } \\
24 \mathrm{hr} .\end{array}$ & $\mid \begin{array}{c}\text { Actual . } \\
\text { kw-hr. for } \\
\mathbf{2 4} \mathrm{hr} .\end{array}$ & $\begin{array}{c}\text { Capacity } \\
\text { in kw-hr. } \\
30 \text { days. }\end{array}$ & $\begin{array}{c}\text { Actual } \\
\text { kw-hr. for } \\
30 \text { days. }\end{array}$ \\
\hline Generators. . & 150 & 4,800 & 800 & 144,000 & 19,200 \\
\hline Fan....... & 40 & 960 & 680 & 28,800 & 18,000 \\
\hline Hoist. . . . . . . & 60 & 1,440 & 336 & 43,200 & 6,080 \\
\hline Elevator. & 20 & 480 & 160 & 14,400 & 2,880 \\
\hline Screen. . & 5 & 120 & 40 & 3,600 & 720 \\
\hline Machine shop. & 5 & 120 & 40 & 3,600 & 1,200 \\
\hline Conveyer.. & 1 & 24 & 8 & 720 & 160 \\
\hline Pumps... & 12 & 288 & 120 & 8,640 & 2,400 \\
\hline Total. . & 293 & 8,232 & 2,184 & 246,960 & 50,640 \\
\hline
\end{tabular}

Load factor for 24-hr. working day $=26.6$ per cent.

30 days $=20.6$ per cent.

In the first column are listed the various machines that are developing power. The second column gives the five-minute peak load for each machine. It will be noticed that for the generators this peak is less than the capacity, but this is almost universally the case in mine power plants. The fan engine runs 
at one speed during 10 hours of a working day, and at a speed requiring about one-half as much power for the remaining 14 hours, and for 24 hours of a non-working day.

The hoist has a peak load of about $300 \mathrm{kw}$. for five seconds, followed by a load of about $150 \mathrm{kw}$. for five seconds. The average time required for each trip will be about 52 seconds, but for intervals of several minutes, this time may be as low as 35 to 38 seconds. The five-minute peak is the average kilowatts for five minutes, with the hoist working at its maximum speed. At the average speed, this peak will be about $42 \mathrm{kw}$.

The third column shows the capacity in kilowatt-hours of each machine if it works 24 hours. The fourth column indicates the actual kilowatt-hours during a 24-hour working day. The ratio of column 4 to column 3 designates the load factor for a 24-hour working day. Column 5 shows the capacity in kilowatthours for 30 days, 24 hours per day. Column 6 shows the actual kilowatt-hours for 30 days. This column is made up of the figures of column 4 for 18 days, plus the kilowatt-hours for 12 non-working days. The ratio between the values of column 6 and column 5 gives the load factor for 30 days. The load factor of a mine plant depends largely on the amount of fan and pump load, and may vary from 13 to 40 per cent.

Table II shows the elements entering into the assumed installation together with the possible savings in these elements when power is purchased.

The interest, depreciation, repairs and upkeep are indicated for each part of the power plant. No saving is figured on the engine building, since it will probably be used for the new motorgenerator and switchboard. This apparatus should be so placed that the hoist engineer can look after its operation during the day. For the night shift a man can be obtained for about $\$ 60$ per month.

In some cases where the generators are modern it may be advisable to retain these generators and purchase motors to drive them. As a rule, the average load on a mine generator is very much below its rated capacity. The peak loads are, however, rather high, so that the generators are really selected in regard to the peak rather than the average load. The type of load curve obtained on a mine generator is shown in some graphic charts in the paper, in the March Procendings of the Institute, entitled "Central Station Power in Coal Mines," by W. A. Thomas. The older types of machines will not stand 
TABLE II.

Cost Based on One Month of 30 Daýs.

Items Included in Cost.

Three engineers at

Two firemen at

One helper at

$\$ 75.00$.

$\$ 50.00$.

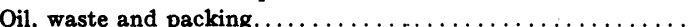

Boilers:

Cost, including stack.

Feed pumps.

Setting and foundation.

Feed water heater.

Interest at 5 per cent.

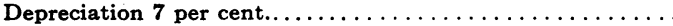

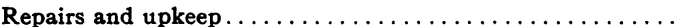

Insurance. . . . . . . . . . . . . . . . .

Boiler Building:

Cost $\$ 2,000.00$

Interest at 5 per cent.

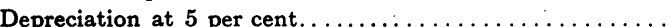

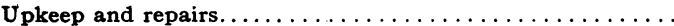

\section{Engines:}

Cost Two generator engines. . . . . . . . .\$3,000.00

Hoist engine . . . . . . . . . . . . . . . 500.00

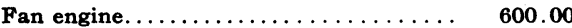

Elevator engine. . . . . . . . . . . . . 200.00

Screen engine................ 150.00

Conveyer engine............. 100.00

Pumps. . . . . . . 400.00

Machine shop engine.......... 150.00

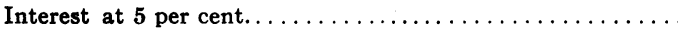

Depreciation at 6 per cent...................

Upkeep and repa....irs. . . . . . . . . . . . . . . .

Building:

Cost $\$ 2,500.00$

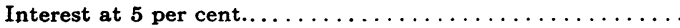

Depreciation at 5 per cent....................

Upkeep and repairs. . . . . . . . . . . . . . . . . . Piping:

Cost $\$ 1,500.00$

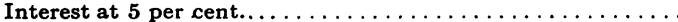

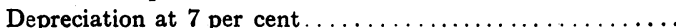

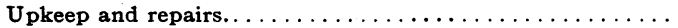

Generator, switchboard and wiring:

Cost $\$ 2,640,00$

Interest at 5 per cent......................

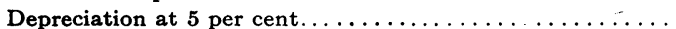

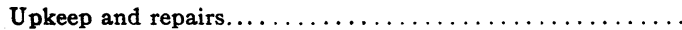

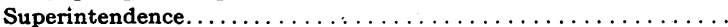

Taxes at 1 per cent. of valuation (assessment 90 per cent.) . . . .

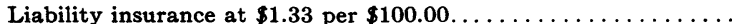

Overhead.
$\$ 4,000.00$

200.00

800.00

400.00

$\$ 5,400.00$

$\$ 6,100.00$

$\begin{array}{cc}\text { Total } & \text { Amt. saved } \\ \text { present } & \text { with }\end{array}$

cost. purchased

150.00

$50.00 \quad 50.00$

$250.00 \quad 250.00$

$50.00 \quad 40.00$

$22.50 \quad 22.50$

$31.50 \quad 31.50$

$50.00 \quad 50.00$

$10.00 \quad 10.00$

$8.35 \quad 8.35$

$8.35 \quad 8.35$

$5.00 \quad 5.00$

$\$ 25.40$

30.50

$\$ 25.40$

30:00

10.40

10.40

5.00

6.25

6.25

$8.75 \quad 8.75$

$15.00 \quad 15.00$

$\$ 11.00$

11. 00

$\$ 11.00$

25. 00

15. 00

6.05

50.00

Total cost.

$\$ 1,165.45$

284.40

$\$ 900.25$

Fixed charges. . . . . . . . .

881.05 
peak loads much beyond their rated capacity, and even if they would, the engines are seldom in condition to take care of these loads. This characteristic of the engines is really a blessing in disguise for the generators. A modern commutating pole generator driven by an induction or synchronous motor can be purchased to give 100 per cent overload for short periods with little or no drop in speed and with good commutation. The retaining of the old generator would require a foundation for the motor, a belt, a coupling and probably an extension to the building. The total cost will about equal the cost of a new motorgenerator set, while the latter will be a much more satisfactory combination. Synchronous converters are also used instead of motor-generator sets, depending upon the local conditions.

The item "superintendence" includes that part of the salaries of the master mechanic and superintendent chargeable to the production of power at the mine in question.

TABLE III.

Cost of New EQUipMENT.

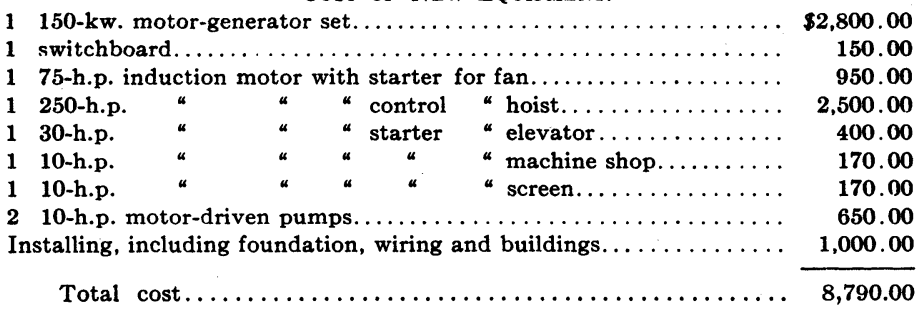

Taxes are figured at 1 per cent per year, on an assessment of 90 per cent of the valuation.

Liability insurance is figured on the pay roll.

"Overhead" includes that part of the salary of the officers and clerks of the company and of the office expenses chargeable to the production of power, and should be the same proportion of the total overhead that the cost of power is to the total cost of production.

The total cost per month is $\$ 1,165.45$, of which $\$ 284.40$ is a fixed charge and $\$ 881.05$ the operating expense. The saving per month with purchased power is $\$ 900.25$. Since the total of kilowatt-hours per month is 50,640 , the total cost of power per kilowatt-hour is $\$ 0.023$. The saving with purchased power will be $\$ 0.0178$ per $\mathrm{kw}-\mathrm{hr}$. The difference between these values or $\$ 0.0052$ is the common cost per kilowatt-hour, which will exist in either case.

In Table III is given a list and cost of the new equipment 
which must be purchased in order to utilize central station energy. Motors are provided to replace the present steam engines. All motors are alternating-current motors, and can be operated at any time, independently of the supply of direct current. In some cases it may be preferable to supply a direct-current motor for the hoist, in which event a larger motor generator is required. This increase may be in the form of a larger generator or of two generators driven by one large motor. One of the generators would be used for the direct-current supply for the mine and the other, with special control, for the hoist. If possible, the old hoist should be sold complete and an entire new electric hoist installed. In the present case, an alternating-

TABLE IV.

SALVAGE on Old EQuipment.

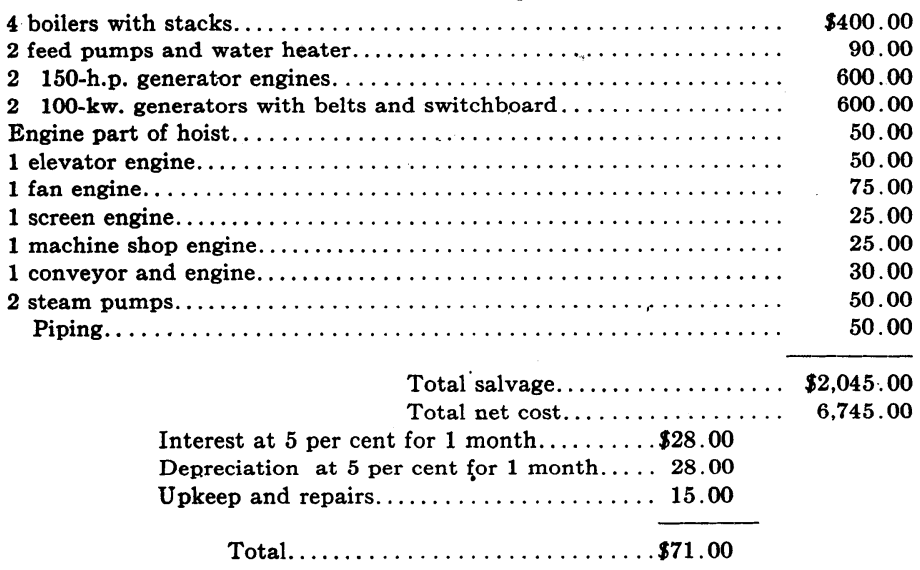

Operating and fixed charges per $k w-h t$. for new equipment. . . . . . .\$0.0014

current motor will be substituted for the steam engine at the hoist. A variable speed alternating-current motor will be supplied for the fan. In many cases air compressors are used to supply air for punchers and pumps. It would be advisable to do away with air compressors entirely, and install electric cutters and motor-driven pumps, as the efficiency of the air system with its usual leaks is very low. However, in gaseous mines, it is sometimes considered dangerous to operate electrical apparatus, in which case a motor-driven compressor should be furnished.

One thousand dollars has been allowed in Table III for the installation of the new apparatus. This should be ample to 
provide for foundations, alterations in building, wiring and mechanical application. The total cost is $\$ 8,790$.

In Table IV is shown the probable salvage that could be obtained for the old apparatus. These estimates should be kept rather low, since it is sometimes difficult to get good prices for old apparatus. The total salvage amounts to $\$ 2,045$. The net cost of new equipment will, therefore, be $\$ 6,745$. The interest, depreciation, upkeep and repairs on the new equipment will amount to $\$ 71.00$ per month. This is at the rate of $\$ 0.0014$ per $\mathrm{kw}$-hr.

In Table $\mathrm{V}$ some specific costs and savings are given. The total cost of power per kilowatt-hour, saving per kilowatthour with purchased power, and the common cost in either case, as before mentioned, are first shown. If the common cost is added to the cost per kilowatt-hour with new equipment, we

TABLE V.-CosTs.

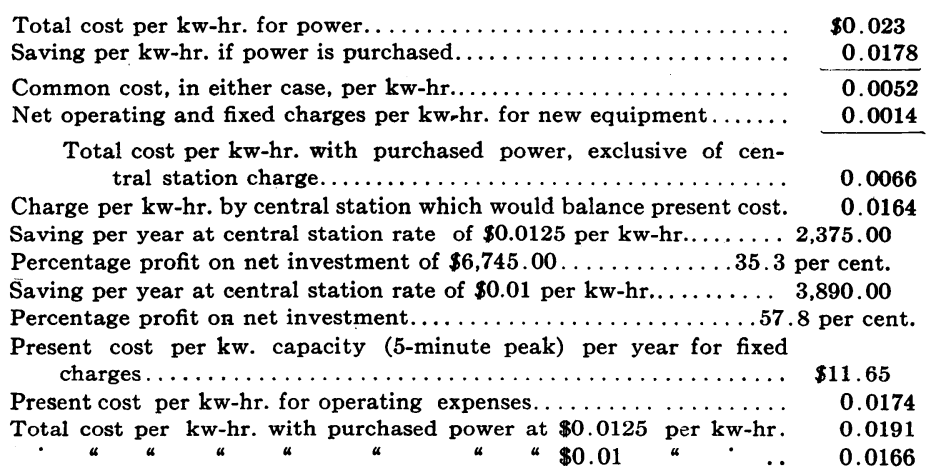

have $\$ 0.0066$ as the total cost per kilowatt-hour with purchased power exclusive of the charge of the central station. If this value of $\$ 0.0066$ is subtracted from the total cost per kilowatt-hour of $\$ 0.023, \$ 0.0164$ is obtained as the central station charge which would make the total cost of power the same as at present. In other words, if the central station rate were $\$ 0.0164$ per $\mathrm{kw}-\mathrm{hr}$. the total cost of power would be the same as at present. Any rate below $\$ 0.0164$ will, therefore, represent a clear saving. At a rate of $\$ 0.0125$ per $\mathrm{kw}-\mathrm{hr}$., the saving would be $\$ 0.0039$ per $\mathrm{kw}-\mathrm{hr}$., or $\$ 2,375$ per year, which is a saving of 35.3 per. cent. over all charges on the new investment. At this rate, the change would pay for itself in less than three years. At a rate of $\$ 0.01$ per $\mathrm{kw}-\mathrm{hr}$., the saving would be $\$ 3,890$, or 57.8 per cent. At this rate, the change would pay for itself in less than two years. 
A coal operator will readily understand that in his isolated plant he will have certain fixed charges which will be practically the same whether his plant operates or not. His power cost can be divided into fixed charges and operating costs. A central station supplying power for his mine will also have a certain part of its total cost as fixed charges. In many cases the fixed charges of the central station will be less than the operator's own fixed charges. The logical basis upon which to charge for central station power would therefore be a certain fixed charge per kilowatt capacity of substation or kilowatt demand, plus a rate per kilowatt-hour which will be equivalent to the operating expense. In the present case, if the fixed charge were made $\$ 12.00$ per year per kilowatt demand on a five-minute peak

TABLE VI.

General Data.

\begin{tabular}{|c|c|}
\hline \multirow{2}{*}{$\begin{array}{l}\text { Average working days per month. } \ldots \ldots \ldots \ldots \ldots \ldots \ldots \ldots \ldots \ldots \\
\text { Electrical kilowatt-hours per working day. } \ldots \ldots \ldots \ldots \ldots \ldots\end{array}$} & \\
\hline & 800 \\
\hline$" \quad " \quad "$ non-working day $\ldots \ldots \ldots \ldots \ldots \ldots$ & 400 \\
\hline Total steam and electric kilowatt-hours per working day................ & 2,184 \\
\hline « $\quad "$ non-working day......... & \\
\hline Maximum electrical kilowatt demand, mqmentary peak.......... & 180 \\
\hline five-minute & 150 \\
\hline \multirow{2}{*}{$\underset{*}{\operatorname{Maximum}}{ }_{*}$ total steam and electric kilowatt demand, momentary peak. } & 450 \\
\hline & 293 \\
\hline \multirow{3}{*}{\multicolumn{2}{|c|}{$\begin{array}{l}\text { Capacity of generators } \ldots \ldots \ldots \ldots \cdots \cdots \cdots \cdots \cdots \\
\text { Total kilowatt-hours per month. } \\
\text { Kilowatt-hours per ton output, based on } 19,800 \text { tons per month }\end{array}$}} \\
\hline & \\
\hline & \\
\hline & \\
\hline Present cost per ton output for power........... & \\
\hline \multicolumn{2}{|l|}{$\begin{array}{c}\text { Cost per ton output for power with central station energy at } \$ 0.0125 \\
\text { per kilowatt-hour. } \ldots \ldots \ldots \ldots \ldots \ldots \ldots \ldots \ldots \ldots \ldots \ldots \ldots \ldots\end{array}$} \\
\hline & \\
\hline
\end{tabular}

basis, the charge per kilowatt-hour would be $\$ 0.0067$ to make the total cost equivalent to $\$ 0.0125$ per $\mathrm{kw}-\mathrm{hr}$. With the fixed charge system the total cost per kilowatt-hour decreases with the amount of power used. This is an incentive for the operator to extend the use of power as much as possible.

There are certain advantages that central station power has over isolated plants that cannot be measured in dollars and cents, and in most cases, even when the fixed charge is the same as the operator would have in his own plant and the charge per kilowatt-hour is equal to his own operating expense, it would still be greatly to his advantage to purchase central station power.

In Table VI is given some general information in regard to 
the results of the tests and investigation that should be made at a mine. The momentary and five-minute electrical peaks are obtained from the graphic records. These graphic records are very interesting and show clearly the extremely fluctuating nature of the load, as well as the low average load. The maximum momentary electrical load is often less than the continuous capacity of the generators. A modern commutating-pole generator of $100-\mathrm{kw}$. capacity would easily take care of the load where two 100-kw. old type machines are used at present. A 150-kw. generator has been figured on to allow for the additional load of the pumps when changed to electric, and also to provide for future extensions. The information given in Table VI will serve as a guide for the central station in determining the capacity of its lines, .transformers, meters, switches, etc. The power required is $2.56 \mathrm{kw}-\mathrm{hr}$. per ton mined. Since the cost per kilowatt-hour is $\$ 0.0234$, the present total cost of power per ton mined will be $\$ 0.0588$.

Summarizing the above information, the following reasons are given to prove the advisability of a mine's purchasing central station energy rather than generating its own power.

1. Lower cost of operation.

2. Worry and care of power plant removed. The legitimate business of a coal operator is to mine and ship coal, and he should not try to carry on another business of so different a nature, at the same time. The efficiency of his plant will be greatly increased if he can spend his entire time in looking after the mining and shipping of the coal.

3. Reliability, which means greater production.

4. Much less expense involved in shutting down mine.

5. Capital needed for new power plant can be used for new development.

6. Increased output and additional power can be obtained quickly with small increase in capital.

7. Increase of production on account of increase of efficiency, due to ample power at all times.

8. No change in speed of fan and pumps due to steam pressure falling occasionally.

About the only disadvantage is that additional capital is often required with which to purchase new apparatus, but when the large returns in the shape of decreased operating expenses are shown, this capital is not difficult to obtain. 